\title{
Cloning, tissue expression pattern and daily rhythms of Period1, Period2, and Clock transcripts in the flatfish Senegalese sole, Solea senegalensis
}

\author{
Águeda J. Martín-Robles · David Whitmore • \\ Francisco Javier Sánchez-Vázquez • Carlos Pendón • \\ José A. Muñoz-Cueto
}

Received: 15 November 2011 / Revised: 13 January 2012 / Accepted: 13 February 2012 / Published online: 29 February 2012 (C) Springer-Verlag 2012

\begin{abstract}
An extensive network of endogenous oscillators governs vertebrate circadian rhythmicity. At the molecular level, they are composed of a set of clock genes that participate in transcriptional-translational feedback loops to control their own expression and that of downstream output genes. These clocks are synchronized with the environment, although entrainment by external periodic cues remains little explored in fish. In this work, partial cDNA sequences of clock genes representing both positive (Clock) and negative (Period1, Period2) elements of the molecular feedback loops were obtained from the nocturnal flatfish Senegalese sole, a relevant species for aquaculture and
\end{abstract}

Communicated by G. Heldmaier.

Á. J. Martín-Robles · J. A. Muñoz-Cueto ( $₫)$

Departamento de Biología, Facultad de Ciencias del Mar y Ambientales, Universidad de Cádiz, Campus de Excelencia Internacional del Mar (CEI MAR), 11510 Puerto Real, Spain e-mail: munoz.cueto@uca.es

Á. J. Martín-Robles · C. Pendón ( $\square)$

Departamento de Biomedicina, Biotecnología y Salud Pública,

Facultad de Ciencias, Universidad de Cádiz,

11510 Puerto Real, Spain

e-mail: carlos.pendon@uca.es

\section{Á. J. Martín-Robles · J. A. Muñoz-Cueto}

CACYTMAR, Institutos de Investigación, Campus

Universitario de Puerto Real, 11510 Puerto Real, Spain

D. Whitmore

Department of Cell and Developmental Biology, Centre for Cell and Molecular Dynamics, University College of London,

London WC1E 6DE, UK

F. J. Sánchez-Vázquez

Departamento de Fisiología, Facultad de Biología,

Universidad de Murcia, 30100 Murcia, Spain chronobiology. All of the above genes exhibited high identities with their respective teleost clock genes, and PerArnt-Sim or basic helix-loop-helix binding domains were recognized in their primary structure. They showed a widespread distribution through the animal body and some of them displayed daily mRNA rhythms in central (retina, optic tectum, diencephalon, and cerebellum) and peripheral (liver) tissues. These rhythms were most robust in retina and liver, exhibiting marked Periodl and Clock daily oscillations in transcript levels as revealed by ANOVA and cosinor analysis. Interestingly, expression profiles were inverted in retina and optic tectum compared to liver. Such differences suggest the existence of tissue-dependent zeitgebers for clock gene expression in this species (i.e., light for retina and optic tectum and feeding time for liver). This study provides novel insight into the location of the molecular clocks (central vs. peripheral) and their different phasing and synchronization pathways, which contributes to better understand the teleost circadian systems and its plasticity.

Keywords Clock genes - Fish - Central nervous system · Liver $\cdot$ Light $\cdot$ Feeding

\section{Introduction}

It is now well established that interlocked feedback loops operate to sustain circadian rhythms in very different model systems such as Cyanobacteria, Neurospora, Drosophila, mouse and zebrafish. At the core of the mammalian circadian clockwork model, Clock and Bmall act as positive regulators, while three Period (Per1, Per2 and Per3) and two Cryptochrome (Cryl and Cry2) genes form the negative regulators. The CLOCK-BMAL1 heterodimer activates the 
transcription of PER and CRY proteins, which interact in the cytoplasm and, after nuclear entry, negatively regulate their own transcription by inhibiting CLOCK and BMAL1 transcriptional activators (Reppert and Weaver 2002). Posttranslational modifications, including phosphorylation of clock proteins, may impact upon the workings of the molecular clock (Lee et al. 2001). This autoregulatory mechanism results in a cyclic, self-sustained expression of clock genes with an approximately $24-\mathrm{h}$ period.

In mammals, outside the suprachiasmatic nucleus ( $\mathrm{SCN})$, the master circadian pacemaker, a number of brain areas as well as peripheral (non-neural) tissues show circadian rhythms in core clock genes (Balsalobre 2002; Guilding and Piggins 2007). These molecular oscillators are differentially reset by periodic external and internal cues. The light-dark (LD) cycle is the most reliable of these time cues and represents a powerful synchronizer of the central clock, whereas peripheral oscillators can be strongly affected by daily feeding cycles (Damiola et al. 2000; Stokkan et al. 2001). Recently, it has been shown that foodrelated cues might also influence the expression of clock genes in the SCN and other multiple brain oscillators (reviewed in Challet and Mendoza 2010). In fish, however, little is known about the role of light and feeding as synchronizers of the molecular clock, although recent research revealed the unique model that fish offers to tackle this issue (Cavallari et al. 2011).

Teleost fish are the largest and most diverse group of vertebrates, showing high divergence in physiology regarding biological rhythms in terms of feeding behavior, locomotor activity and reproductive strategies, which reflects the evolution of complex and diverse timekeeping mechanisms (Falcon et al. 2010; Migaud et al. 2007). Therefore, fish represent very attractive models to study circadian clocks (Lahiri and Foulkes 2010). As in mammals, rhythmic clock gene expression has been described in fish in central and peripheral tissues, although a larger number of clock genes have been identified derived from a teleost-specific genome duplication (Meyer and Van de Peer 2005). Moreover, in zebrafish (Danio rerio), peripheral tissues and cells lines have been shown to be light responsive (Tamai et al. 2005; Whitmore et al. 2000), which allows direct entrainment of peripheral circadian clocks independently from the central oscillator. Interestingly, in most recent works, entrainment of central (brain) and peripheral (liver) tissues by both light and feeding cycles has also been demonstrated in fish (Cavallari et al. 2011; Feliciano et al. 2011; Lopez-Olmeda et al. 2010).

The Solea senegalensis is a flatfish with nocturnal locomotor and feeding rhythms (Bayarri et al. 2004; Navarro et al. 2009), marked daily and seasonal plasma melatonin rhythms (Oliveira et al. 2010; Vera et al. 2007), reproduc- tion and development (Blanco-Vives et al. 2011a; Confente et al. 2010; Isorna et al. 2009, 2011; Oliveira et al. 2009). This flatfish has a great commercial value and is of particular interest to chronobiologists as sole experiences a lightdependent switch (from diurnal to nocturnal) of its daily activity rhythms during metamorphosis (Blanco-Vives et al. 2012) and exposure of larvae to daily thermocycles alters the timing of gonad development and sex ratio (Blanco-Vives et al. 2011b). However, the molecular bases underlying sole circadian rhythms remain to be deciphered. In a preliminary study, we cloned a full-length coding cDNA sequence of Senegalese sole Per3, which showed a significant daily oscillation in visually related structures such as the retina and the optic tectum (Martin-Robles et al. 2011). The aim of this research was to extend our knowledge about the molecular clock components and its regulation in this species, by investigating positive (Clock) and negative (Perl and Per2) elements of the transcriptiontranslation feedback loops, their tissue distribution and their daily rhythms in central versus peripheral tissues.

\section{Materials and methods}

Animals and sampling

Adult vitellogenic female sole specimens from 200 to $300 \mathrm{~g}$ in body mass were housed in the "Laboratorio de Cultivos Marinos" (University of Cadiz, Puerto Real, Spain). Animals were kept in running seawater at a constant temperature and salinity of $19 \pm 1^{\circ} \mathrm{C}$ and $39 \mathrm{ppt}$, respectively, in indoor facilities receiving natural environmental light $(12 \mathrm{~h}$ light:12 h darkness), with lights on at ZT0. Fish were fed by automatic feeders three times a day between ZT5-ZT8, ZT11-ZT14 and ZT17-ZT20 with commercial 2-mm dry pellets (Skretting España S.A, Burgos, Spain) and a daily ration of about $1 \%$ body weight. Fish were fasted for $24 \mathrm{~h}$ before sampling. They were anesthetized in MS-222 (Sigma, St Louis, MO; 100-200 mg/l of water) before killing. This study was approved by the Animal Experimentation and Ethics Committee of the University of Cádiz (Spain) and was conducted according to international ethical standards.

For the partial cloning and the tissue distribution study, fish were killed during daytime between Zeitgeber Time (ZT) 3 and ZT5 for sole Per1 and Per2, and during the night between ZT14 and ZT15 for Clock, and neural (olfactory bulbs, telencephalon, optic tectum, diencephalon, cerebellum, medulla, retina) and peripheral (pituitary, gills, heart, liver, kidney, intestine, and ovary) tissues were collected.

To analyze daily transcript levels of Per1, Per2, and Clock, 36 sole specimens from the same broodstock were 
Table 1 Sequences of primers used for the Perl, Per2, and Clock partial cloning, RT-PCR and qPCR expression analysis. The different PCR product sizes are also indicated

\begin{tabular}{|c|c|c|}
\hline Primer name & Sequence $\left(5^{\prime}-3^{\prime}\right)$ & $\begin{array}{l}\text { PCR product } \\
\text { size (bp) }\end{array}$ \\
\hline \multicolumn{3}{|l|}{ Molecular cloning } \\
\hline PER1F1 & GGAGAGCAACAAGAGCTCMAAC & \multirow[t]{2}{*}{715} \\
\hline PER1R2 & GCGATGAGCAGGCAGCAGGGCT & \\
\hline DRPER2F283 & CAGTGTGTTCTACAGCTTCACCAC & \multirow[t]{2}{*}{499} \\
\hline DRPER2R284 & AAGCTGGACCAGCTGGTGTC & \\
\hline CLOCKF1 & CAGTTCAATGTSCTCATCAAGGA & \multirow[t]{2}{*}{613} \\
\hline CLOCKR1 & GTGCACATYTCCTTGATAAACTG & \\
\hline \multicolumn{3}{|c|}{ Tissue expression pattern } \\
\hline SSPER1F5 & GGAGCTGAAGCTGCGTCTGCC & \multirow[t]{2}{*}{216} \\
\hline SSPER1R7 & TTGAGGGTGTATTCGGAGGTGA & \\
\hline SSPER2F8 & AACAGTTCTGCTGCCTCCTGCTG & \multirow[t]{2}{*}{219} \\
\hline SSPER2R3 & GCATTAACGGTCGGTCACTTGGG & \\
\hline SSCLOCKF1E & AAGGAAATCGCTGCTCAGTCGG & \multirow[t]{2}{*}{385} \\
\hline SSCLOCKR1E & CATATTCGTACACAGGAGGCTCT & \\
\hline SSACTINF & GACATGGAGAAGATCTGGCATCA & \multirow[t]{2}{*}{488} \\
\hline SSACTINR & GGCAGCTCATAGCTCTTCTCC & \\
\hline \multicolumn{3}{|l|}{ Real-time qPCR } \\
\hline SSPER1qPCRF1 & ACATCACCTCCGAATACACC & \multirow[t]{2}{*}{141} \\
\hline SSPER1qPCRR1 & ACACAGACCCCTGAAGACAC & \\
\hline SSPER2qPCRF1 & TGAGCTCGCTGAAGAACAG & \multirow[t]{2}{*}{108} \\
\hline SSPER2qPCRR1 & TGTGTGGTGGTGAAGATGC & \\
\hline SSCLOCKqPCRF1 & TATCATGGAGGGAGAGACA & \multirow[t]{2}{*}{173} \\
\hline SSCLOCKqPCRR1 & TTCGGGTACAGTTAGGCAC & \\
\hline SSACTB2F & AATCGTGACCTCTGCTTCCCCCTGT & \multirow[t]{2}{*}{92} \\
\hline SSACTB2R & TCTGGCACCCCATGTTACCCCATC & \\
\hline SSRPS4F & GTGAAGAAGCTCCTTGTCGGCACCA & \multirow[t]{2}{*}{83} \\
\hline SSRPS4R & AGGGGGTCGGGGTAGCGGATG & \\
\hline
\end{tabular}

sampled every $4 \mathrm{~h}$ ( $n=6$ at each point) over a 24-h LD cycle corresponding to ZT0, ZT4, ZT8, ZT12, ZT16, and ZT20 (sunrise 07:28; sunset 19:20). Neural (retina, optic tectum, diencephalon, cerebellum) and peripheral (liver) tissues were rapidly removed as previously reported (Martin-Robles et al. 2011). At night, sampling was performed under a dim red light. All samples were frozen immediately in liquid nitrogen and stored at $-80^{\circ} \mathrm{C}$ until use.

Partial molecular cloning of sole Per1, Per2, and Clock cDNAs

Total RNA was extracted from a pool of sole retinas by using the TRIsure Reagent ${ }^{\circledR}$ (Bioline, London, UK) according to the manufacturer's instructions. An aliquot of $2 \mu \mathrm{g}$ was DNase I-treated (USB, Cerdanyola, Spain) and reverse transcribed to cDNA in a $20-\mu \mathrm{l}$ reaction volume using oligo- $\mathrm{dT}_{20}$, random hexamers and the SuperScrip ${ }^{\circledR}$ III Reverse Transcriptase (Invitrogen, Carlsbad, CA, USA). Partial cDNA fragments were amplified by using touch- down polymerase chain reactions (PCR) using the Advantage ${ }^{\circledR} 2$ PCR kit (BD Bioscience, Clontech, Palo Alto, CA, USA) or the GoTaq $^{\circledR}$ Flexi DNA Polymerase (Promega, Madison, WI, USA). PCR were performed using optimized degenerated primers designed by means of ClustalW2 algorithm (http://www.ebi.ac.uk/Tools/clustalw2/) from highly conserved regions among the available vertebrate clock genes sequences (Table 1). PCR conditions for Perl and Per 2 were set as follows: $95^{\circ} \mathrm{C}$ for $2 \mathrm{~min}, 5$ cycles of $95^{\circ} \mathrm{C}$ for $5 \mathrm{~s}, 68^{\circ} \mathrm{C}$ for $3 \mathrm{~min}, 5$ cycles of $95^{\circ} \mathrm{C}$ for $5 \mathrm{~s}, 66^{\circ} \mathrm{C}$ for $3 \mathrm{~min}$, and 30 cycles of $95^{\circ} \mathrm{C}$ for $5 \mathrm{~s}, 64^{\circ} \mathrm{C}$ for $3 \mathrm{~min}$. A final extension step was added at $66^{\circ} \mathrm{C}$ for $5 \mathrm{~min}$. For Clock, similar amplification conditions were used, but annealing-extension temperatures were set at 70,68 and $66^{\circ} \mathrm{C}$

Amplified products were gel purified with Eppendorf Perfectprep ${ }^{\circledR}$ Gel Cleanup Kit (Eppendorf, Hamburg, Germany) and subcloned into pGEM $^{\circledR}$-T Easy vector system (Promega) following commercially available protocols. Five positive clones per fragment were sequenced using the 
BigDye ${ }^{\circledR}$ Terminator v3.0 Ready Reaction Cycle Sequencing Kit in the ABI PRISM 3100 Genetic Analyzer (Applied Biosystems, Carlsbad, CA, USA) with vector specific primers (T7 and SP6).

\section{Sequence analysis}

The identity of the partial sole cDNA fragments was confirmed by BLAST (http://blast.ncbi.nlm.nih.gov/) and deduced amino acid sequences were obtained using the ExPASy Proteomics Server (http://www.expasy.ch/). Conserved domains were determined using the Simple Modular Architecture Research Tool (SMART, http://smart.emblheidelberg.de/). Phylogenetic analysis was accomplished by comparing sole sequences with complete sequences of PER and CLOCK proteins available in the GenBank and Ensembl databases. The tree was constructed by using the neighbor-joining method with the Phylo_win 2.0 software (Galtier et al. 1996), and bootstrap analysis with 1,000 replications was used to test the strictness of the tree.

Tissue expression analysis of sole clock genes by RT-PCR

Total RNA from a pool of sole neural and peripheral tissues was extracted as described above. Aliquots of $100 \mathrm{ng}$ were digested with DNase I (USB) to eliminate genomic DNA and retro-transcribed with the iScript cDNA synthesis kit (Bio-Rad, Alcobendas, Spain). Specific primers were designed using the Oligo Explorer v 1.1.0 software [T. Kuulasma, University of Kuopio, Kuopio, Finland (http:// www.uku.fi/ kuulasma/OligoSoftware)] from the sequences previously obtained (Table 1), and PCR were performed with the BIOTAQ ${ }^{\mathrm{TM}}$ DNA polymerase (Bioline). PCR conditions were set at $94^{\circ} \mathrm{C}$ for 2 min followed by 30 cycles of denaturation at $94^{\circ} \mathrm{C}(15 \mathrm{~s})$, annealing at 58 , 62 and $55^{\circ} \mathrm{C}(30 \mathrm{~s})$ for Per $1, P e r 2$, and Clock, respectively, extension at $72^{\circ} \mathrm{C}(30 \mathrm{~s})$ and completed at $72^{\circ} \mathrm{C}$ for $5 \mathrm{~min}$. Amplified products were visualized in $1.2 \%$ agarose gels with ethidium bromide, and then sequenced to verify their identities. Sole $\beta$-actin (Genbank accession number DQ485686) was used as the internal control gene. Signal intensity of amplified products was estimated using the Quantity one ${ }^{\circledR}$ 4.2.1 software (Bio-Rad) and represented referring to the $\beta$-actin signal.

Real-time quantitative PCR expression analysis

Total RNA was extracted from retina, optic tectum, diencephalon, cerebellum, and liver using TRIsure Reagent ${ }^{\circledR}$ (Bioline) and $100 \mathrm{ng}$ was reverse transcribed with the Quantitec $^{\circledR}$ Reverse Transcription Kit (Qiagen, Hilden, Germany). Real-time quantitative PCR (RT-qPCR) reactions were developed in a Chromo $4^{\mathrm{TM}}$ Four-Color Real-Time
System (Bio-Rad) as previously described (Martin-Robles et al. 2011). Specific primers for sole Perl, Per2, and Clock were designed using the Primer3 v 0.4.0 software (Whitehead Institute for Biomedical Research, Cambridge, MA, Table 1). PCR conditions were set as follows: initial denaturation and enzyme activation at $95^{\circ} \mathrm{C}$ for $2 \mathrm{~min}, 40$ cycles of denaturation at $95^{\circ} \mathrm{C}$ for $10 \mathrm{~s}$, and annealing-extension at $58.3^{\circ} \mathrm{C}$ for $35 \mathrm{~s}$. Sole $\beta$-actin and ribosomal protein $\mathrm{S} 4$ Rps 4 (GeneBank accession number AB291557) were selected as housekeeping genes, using the PCR conditions detailed in Martin-Robles et al. (2011). Standard curves were generated for each gene with tenfold serial dilutions of cDNA and all calibration curves exhibited slopes close to -3.32 and efficiencies around $100 \%$. Melting curves were generated for each sample to confirm that a single product was amplified. Non-template controls and non-retro-transcribed total RNA samples were used as negative controls. The $\Delta \Delta \mathrm{Ct}$ method (Livak and Schmittgen 2001) was used to determine the relative mRNA expression.

Data analysis

Statistical variations in sole clock genes mRNA levels among different daily time points were analyzed by oneway ANOVA followed by post hoc LSD multiple comparisons test. When necessary, values were transformed to get normal distribution and homogeneity of variances. In all cases, statistical significance was accepted at $p<0.05$. All statistical tests were made using Statgraphics Plus 5.1 software (Statpoint Technologies, Warrenton, VA, USA). Rhythm analyses were performed by the cosinor method (Nelson et al. 1979), using the software developed by Prof. A. Díez Noguera ("El Temps", University of Barcelona) and they were considered significant when $p<0.05$.

\section{Results}

Molecular cloning of Senegalese sole clock genes

Partial Perl, Per2, and Clock cDNA fragments were 715, 499, and 613 base pairs (bp), respectively (GenBank accession numbers FM180505, FM200425 and FM179317), from which 238, 166, and 204 partial amino acid (aa) sequences were deduced. Conserved Per-Arnt-Sim (PAS) binding domains were identified in sole partial PER1 and PER2 predicted proteins and a basic helix-loop-helix (bHLH) DNA binding domain was found in sole partial CLOCK (data not shown). These sole PER1, PER2, and CLOCK fragments exhibited identities between 78-90, 7988 , and $83-95 \%$, respectively, when compared with their respective teleost clock proteins. The identity was lower with other non-fish vertebrate sequences and fluctuated 


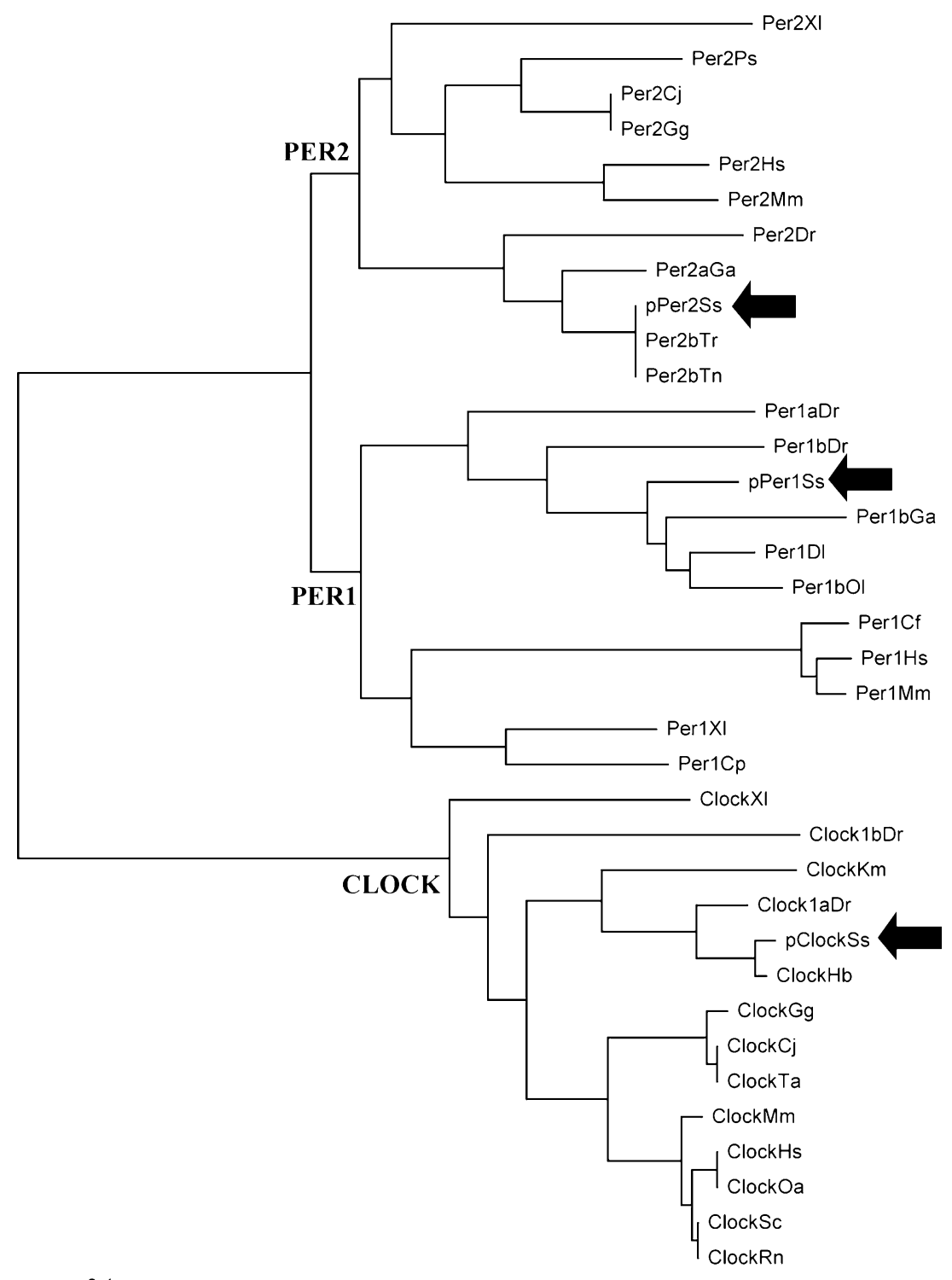

Fig. 1 Phylogenetic tree of PER and CLOCK proteins created by the neighbor-joining method. Only complete protein sequences were used for the analysis. The length of the branches is proportional to the phylogenetic distance. Solea senegalensis circadian proteins positions are indicated by black arrows. Cf, Canis familiaris; $\mathrm{Cj}$, Coturnix japonica; Cp, Cynops pyrrhogaster; Dl, Dicentrarchus labrax; Dr, Danio rerio; $\mathrm{Ga}$, Gasterosteus aculeatus; Gg, Gallus gallus; Hb, Haplochromis burtoni; Hs, Homo sapiens; Km, Kryptolebias marmoratus; Mm, Mus musculus; Oa, Ovis aries; Ol, Oryzias latipes; Ps, Podarcis sicula; Sc, Spalax carmeli; Rn, Rattus norvegicus; Ss, Solea senegalensis; Ta, Tyto alba; Tn, Tetraodon nigroviridis; Tr, Takifugu rubripes; Xl, Xenopus laevis. Protein accession numbers and Ensembl protein IDs used for alignment and phylogenetic analysis were the following: ENSCAFP00000025009 (Canis familiaris PER1); BAB03455, BAB03454, (Coturnix japonica PER2, CLOCK); BAC98490 (Cynops pyrrhogaster PER1); GQ353293 (Dicentrarchus labrax PER1); NP_001025354,NP_997604, NP_878277, NP_571032, NP_840080

between 60 and 64\% for sole PER1, 61-69\% for PER2, and $72-77 \%$ for CLOCK. This result was confirmed by the phylogenetic analysis that clearly located sole PER1, PER2,
(Danio rerio PER1a, PER1b, PER2, CLOCK1a, CLOCK1b); ENSGACP00000025523, ENSGACP00000017830 (Gasterosteus aculeatus PER1b, PER2a); NP_989593, NP_989505 (Gallus gallus PER2, CLOCK); ABP97104 (Haplochromis burtoni CLOCK); NP_002607, NP_073728, NP_004889 (HsPER1, PER2, CLOCK); ACL00861 (Kryptolebias marmoratus CLOCK); NP_001152839, NP_035196; NP_031741 (Mus musculus PER1, PER2, CLOCK); NP_001124404 (Ovis aries CLOCK); NP_001129992 (Oryzias latipes PER1b); CAI43981 (Podarcis sicula PER2); Q91YB2 (Spalax carmeli CLOCK); NP_068628 (Rattus norvegicus CLOCK); FM180505, FM200425, FM179317 (present work, Solea senegalensis pPER1, pPER2, pCLOCK); Q6YGZ4 (Tyto alba CLOCK); GSTENP00026769001(Tetraodon nigroviridis, PER2b); SINFRUP00000174412, (Takifugu rubripes PER2b); NP_001079172, NP_001081098, NP_001083854 (Xenopus laevis PER1, PER2, CLOCK)

and CLOCK within the corresponding fish branches, showing higher divergence in relation to amphibian, avian, and mammalian sequences (Fig. 1). 
Tissue distribution of Perl, Per2, and Clock genes

RT-PCR analysis using sole specific primers revealed clock genes expression in almost all central and peripheral tissues examined (Fig. 2a). In central tissues, a conspicuous band was observed in retina, cerebellum and, to a lesser extent, in diencephalon, olfactory bulbs, pituitary, optic tectum, telencephalon, and medulla oblongata (Fig. 2a-d). In the case of Per2, cDNA amplification was not detected in telencephalon and medulla oblongata (Fig. 2a, c). In peripheral tissues, intense signal was observed in ovary for the three genes analyzed, as well as in liver and gill for Perl. A moderate band was present for Perl in the remaining tissues, whereas moderate to faint signals were found for Per 2 and Clock in most peripheral tissues analyzed (Fig. 2a-d).

Daily expression of clock genes in central and peripheral tissues

We analyzed the daily rhythms of Perl, Per2, and Clock transcripts in central tissues such as retina, optic tectum, diencephalon, and cerebellum (Figs. 3, 4, 5, 6; Table 2). These tissues were selected because they have been implicated in the processing of visual/light information and contain melatonin binding sites and express melatonin receptors in sole (Oliveira et al. 2008; Confente et al. 2010). The liver was also selected (Fig. 7; Table 2), because it exhibited an important expression of clock genes in the RT-PCR study and feeding-entrained liver oscillators have been reported in fish (Cavallari et al. 2011; Feliciano et al. 2011; Lopez-Olmeda et al. 2010). In all tissues examined, Per2 expression was significantly lower than those of Per1 and Clock (compare the scales of $y$ axis in Figs. 3, 4, $5,6,7)$. In retina, cerebellum and especially in liver, the highest expression was found for Perl, while in diencephalon it was observed for Clock. In optic tectum, both genes showed similar expression levels.

Statistical analysis including cosinor and ANOVA indicated differences in phase depending on the tissue analyzed (Figs. 3, 4, 5, 6, 7; Table 2). Retina and liver were the most rhythmic tissues. In retina, Perl and Clock but not Per2 transcript levels displayed significant cyclic oscillations over the 24-h cycle (Fig. 3a-c; Table 2). Perl expression diminished during the day and significantly increased during the dark phase, showing its acrophase during midnight, at ZT 18.12 (Fig. 3a; Table 2). In contrast, Clock mRNA levels were higher during the light phase and decreased in the nighttime, with the acrophase positioned at midday (ZT 6.38, Fig. 3c; Table 2). In optic tectum, only Perl transcripts exhibited significant daily rhythms by both ANOVA and cosinor analysis (Fig. 4a-c; Table 2). Its expression decreased during the light phase and the early night, but it increased in the second half of the night and peaked near

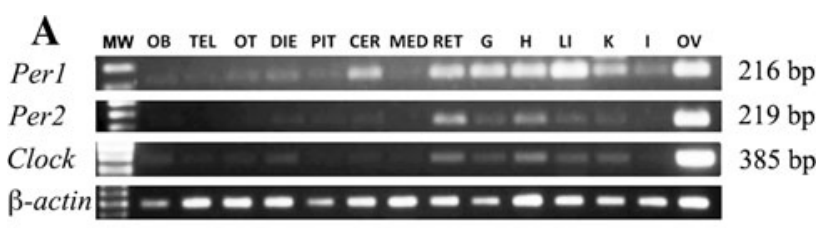

$$
\text { B }
$$

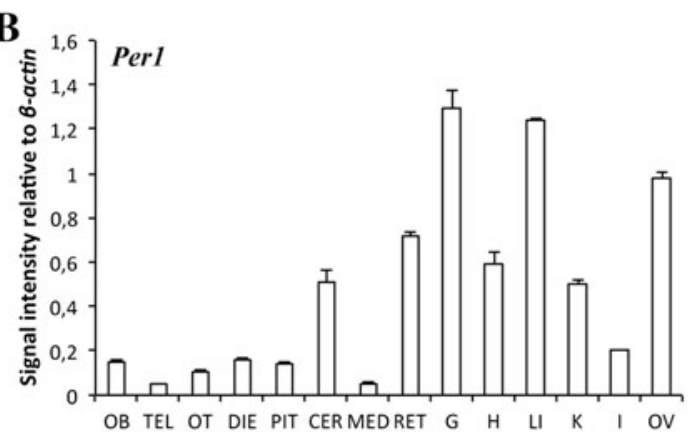

C

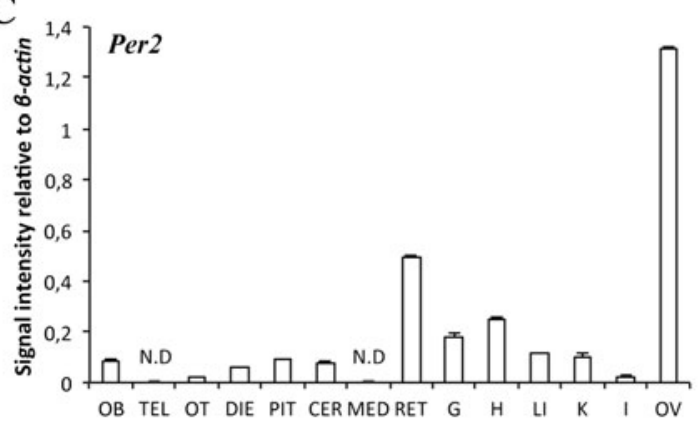

D

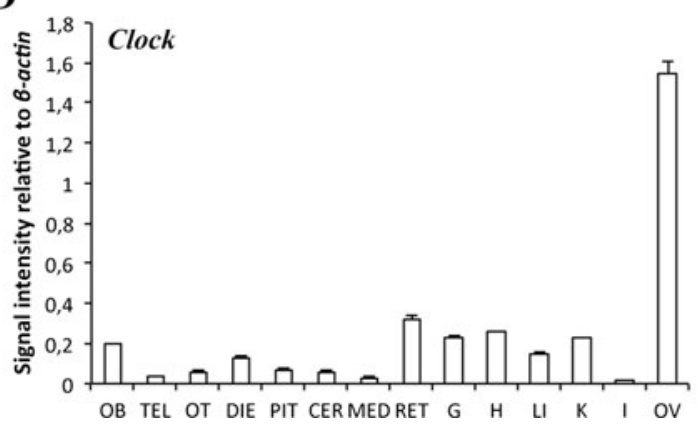

Fig. 2 Tissue distribution of Senegalese sole clock genes in central and peripheral tissues. a Specific Per1, Per2, and Clock products of 216, 219, and $385 \mathrm{bp}$, respectively, were amplified following the RTPCR conditions described in "Materials and methods". Sole $\beta$-actin was used as internal control gene (lower panel). b-d Signal intensity of above amplified products relative to $\beta$-actin for Per1 (b), Per 2 (c), and Clock (d) was calculated by using the Quantity one ${ }^{\circledR}$ software (Bio-Rad). Columns represent the mean \pm SEM of three different measurements. Per2 signal was not detected in telencephalon and medulla. $M W$ molecular weight marker (100-bp Dominion, Córdoba, Spain), $O B$ olfactory bulbs, TEL telencephalon, $O T$ optic tectum, DIE diencephalon, PIT pituitary, CER cerebellum, MED medulla, RET retina, $G$ gills, $H$ heart, $L I$ liver, $K$ kidney, $I$ intestine, $O V$ ovary, N.D. nondetected

dawn (ZT 22.27, Fig. 4a; Table 2). Per2 mRNA levels showed significant daily variations only by ANOVA, its expression being higher at ZT4, during the daytime (Fig. 4b). In the diencephalon, only Per2 transcript levels 

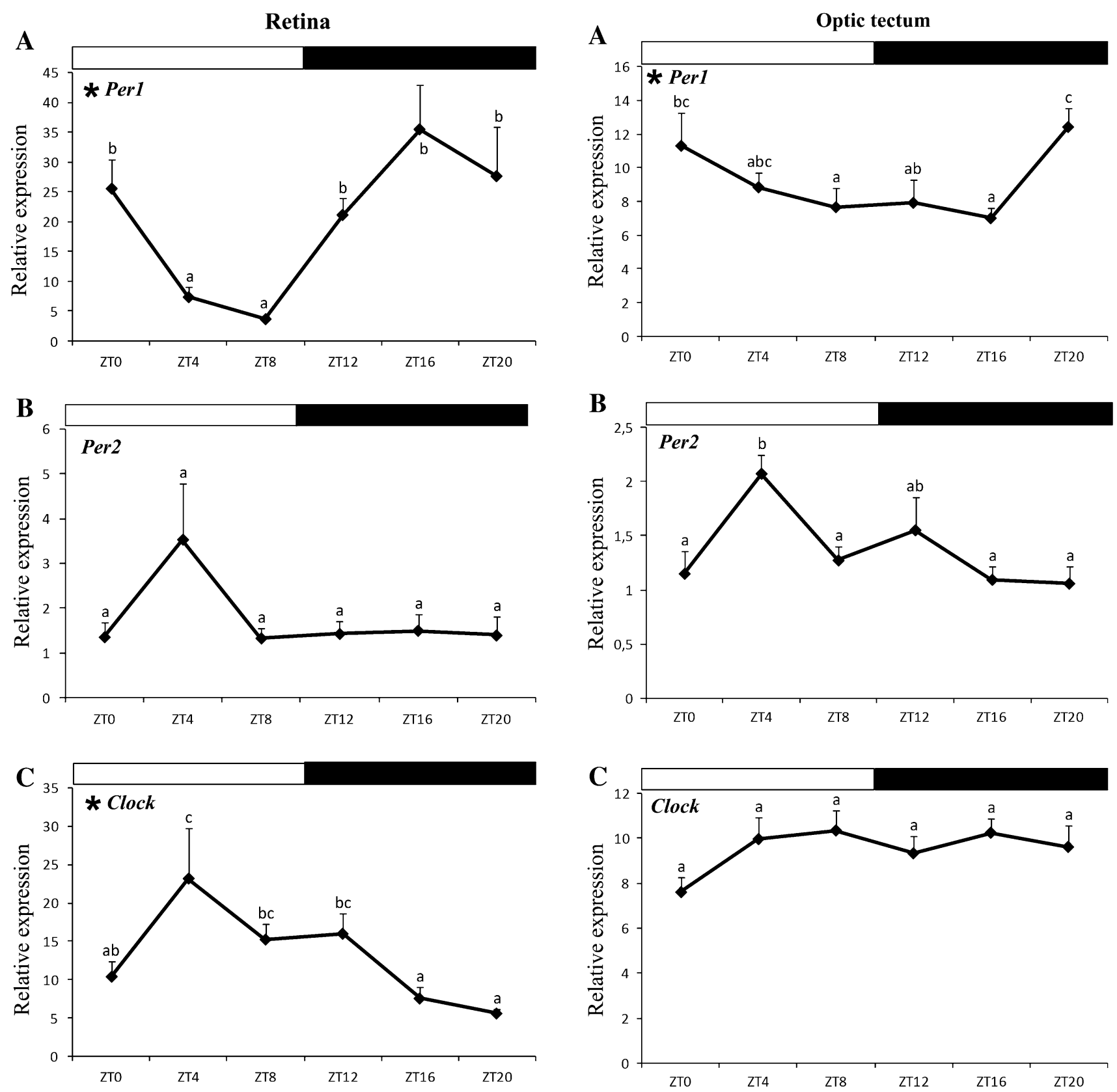

Fig. 3 Relative expression of Per1 (a), Per2 (b), and Clock (c) in Senegalese sole retina during the daily light-dark (LD) cycle. Samples were taken every $4 \mathrm{~h}$ and each value represents the mean \pm SEM of six different specimens $(n=6)$. The bars above each graph indicate the daily photoperiod conditions. White bars represent the light phase (sampling points ZT0, ZT4 and ZT8) and black bars represent phases of darkness (sampling points ZT12, ZT16 and ZT20). Different letters indicate statistically significant differences between mean values $(p<0.05)$. The asterisk indicates a significant rhythm by cosinor analysis (see Table 2 for details)

were revealed as rhythmic by ANOVA and cosinor analysis (Fig. 5b; Table 2). Its expression peaked near the mid of the light phase at ZT 5.27, and decreased toward the end of the night. In cerebellum, none of the clock genes investigated

Fig. 4 Relative expression of Per1 (a), Per2 (b), and Clock (c) in Senegalese sole optic tectum during the daily LD cycle. For further details, see the legend of Fig. 3

was found to be rhythmic by both ANOVA and cosinor analysis, although Clock expression values support the cosinor analysis $(p<0.05)$, showing its acrophase in the early night at ZT 15.42 (Fig. 6c; Table 2).

Finally in liver, significant daily rhythms were observed for Per1 and Clock but not for Per2 (Fig. 7a-c; Table 2). Opposite to the retina and the optic tectum, Perl expression increased during daytime, peaked at ZT 9.59, and started to decline in the day-night transition, showing its minimum values near midnight (Fig. 7a; Table 2). Clock mRNA 

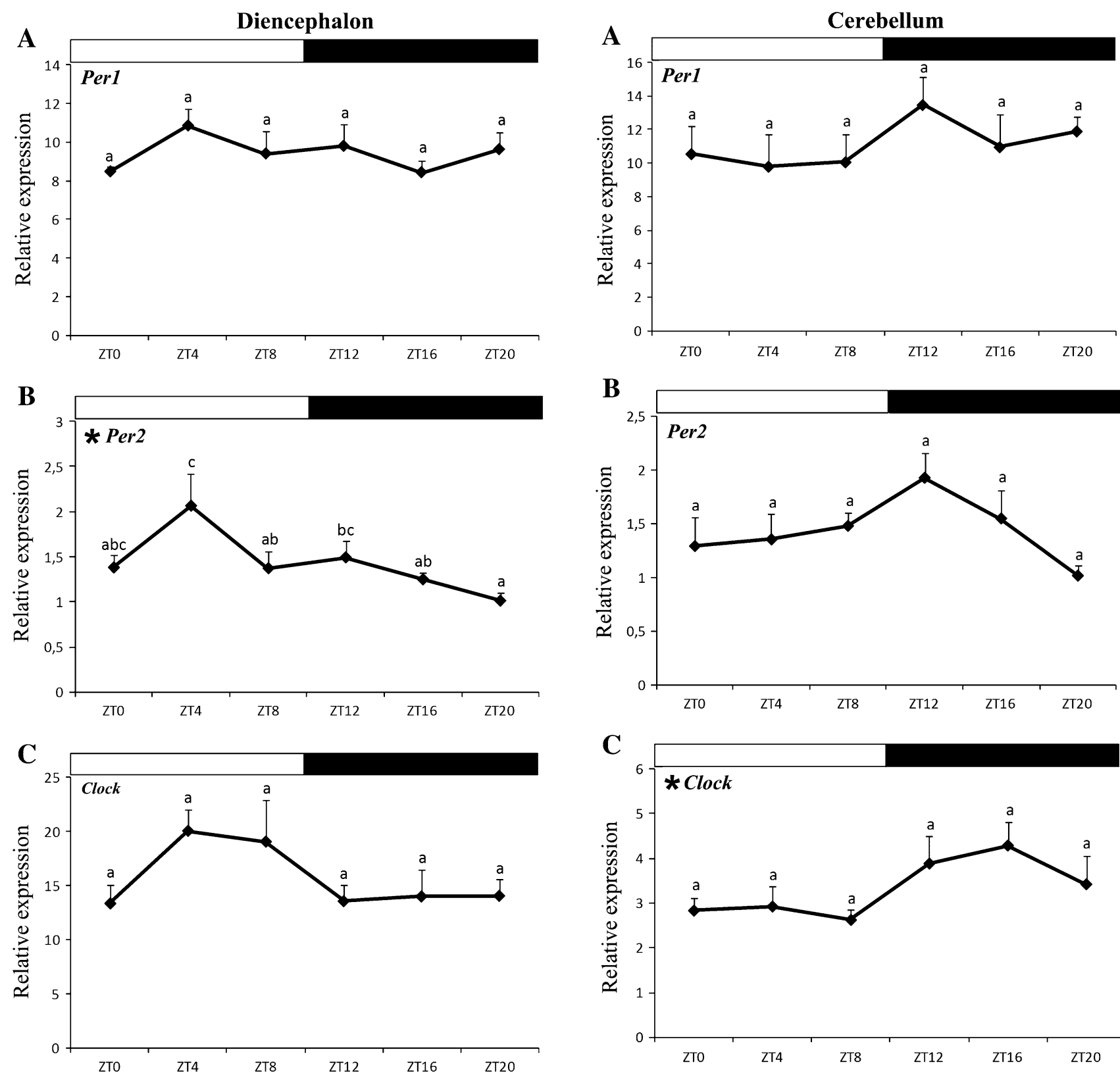

Fig. 5 Relative expression of Per1 (a), Per2 (b), and Clock (c) in the diencephalon of Senegalese sole during the daily LD cycle. For further details, see the legend of Fig. 3

levels also exhibited an inverse daily pattern in liver in relation to the rhythmic central tissues. Its expression remained low during daytime and the early night, increasing during the rest of the dark phase (Fig. 7c). Clock acrophase was observed around the mid of the night at ZT 18.56 (Table 2).

\section{Discussion}

In the present study performed in Senegalese sole, we have cloned cDNA sequences corresponding to partial coding

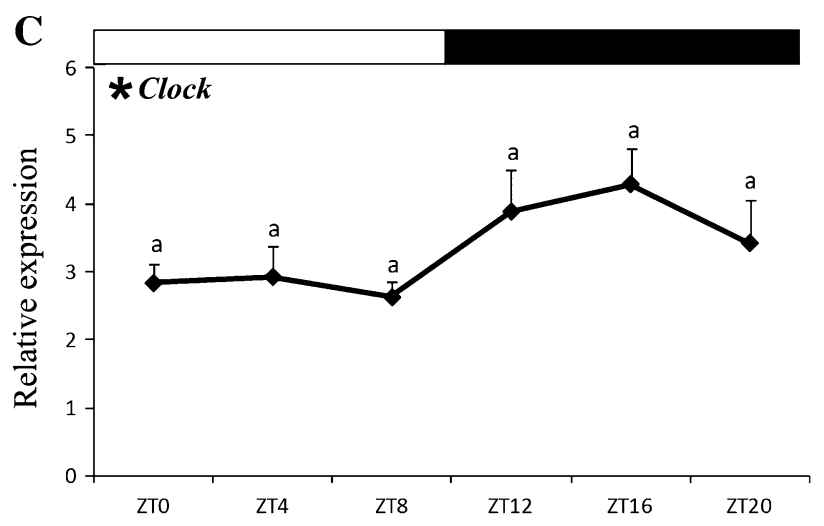

Fig. 6 Relative expression of Perl (a), Per2 (b), and Clock (c) in the cerebellum of Senegalese sole during the daily LD cycle. For further details, see the legend of Fig. 3

regions of Per1, Per2, and Clock, three of the main clock genes in vertebrates. Expression of these genes shows a broad tissue distribution in this species, some of them exhibiting significant daily rhythms in retina, optic tectum, diencephalon, and liver. In all tissues analyzed, Perl always precedes the Per3 acrophase (Martin-Robles et al. 2011) and both genes are able to anticipate dawn in retina and brain, as their expression is activated before sunrise. Furthermore, Per genes oscillate in anti-phase to the oscillations displayed by Clock, which is consistent with their putative roles as negative and positive elements of the clock mechanism in mammals and fish (Pando and Sassone-Corsi 2002). 
Table 2 Parameters defining clock gene expression rhythms in central and peripheral tissues of sole

\begin{tabular}{|c|c|c|c|c|}
\hline & $\begin{array}{l}\text { Mesor } \\
\text { (r.e.) }\end{array}$ & $\begin{array}{l}\text { Amplitude } \\
\text { (r.e.) }\end{array}$ & $\begin{array}{l}\text { Acrophase } \\
\text { (ZT) }\end{array}$ & $\begin{array}{l}\text { Significance } \\
(p \text {-value) }\end{array}$ \\
\hline \multicolumn{5}{|l|}{ Retina } \\
\hline Perl & 20.12 & 14.94 & 18.12 & 0.0002 \\
\hline Per2 & 1.68 & 0.50 & 4.01 & N.S. $p>0.2$ \\
\hline Clock & 12.71 & 6.81 & 6.38 & 0.001 \\
\hline \multicolumn{5}{|c|}{ Optic tectum } \\
\hline Perl & 9.26 & 2.37 & 22.27 & 0.009 \\
\hline Per2 & 1.35 & 2.37 & 6.13 & N.S. $p>0.05$ \\
\hline Clock & 9.48 & 0.74 & 11.12 & $p>0.3$ \\
\hline \multicolumn{5}{|c|}{ Diencephalon } \\
\hline Perl & 9.45 & 0.63 & 5.39 & N.S. $p>0.4$ \\
\hline Per2 & 1.42 & 0.35 & 5.27 & 0.01 \\
\hline Clock & 15.66 & 3.19 & 5.52 & N.S. $p>0.07$ \\
\hline \multicolumn{5}{|c|}{ Cerebellum } \\
\hline Perl & 11.08 & 1.22 & 14.56 & N.S. $p>0.4$ \\
\hline Per2 & 1.44 & 0.32 & 11.12 & N.S. $p>0.05$ \\
\hline Clock & 3.33 & 0.77 & 15.42 & 0.02 \\
\hline \multicolumn{5}{|l|}{ Liver } \\
\hline Perl & 66.06 & 33.97 & 9.59 & 0.002 \\
\hline Per2 & 2.45 & 0.71 & 20.22 & N.S. $p>0.2$ \\
\hline Clock & 10.82 & 9.82 & 18.56 & 0.001 \\
\hline
\end{tabular}

Numeric values of mesor, amplitude, and acrophase, as well as the significance of the rhythms ( $p$-value) reported by the cosinor analysis are presented for all genes and tissues studied. Mesor and amplitude are given as relative expression values (r.e.) and acrophases as Zeitgeber Time (ZT) hours. Rhythms were considered significant when $p<0.05$ N.S. nonsignificant

In silico structural analysis of the partial amino acid sequences indicated the presence of PAS and bHLH domains. Both domains are highly conserved among PER and CLOCK transcription factors from different species, and are required for the proper functioning of the circadian clock (Hirayama and Sassone-Corsi 2005). The phylogenetic tree grouped the sole PER1, PER2, and CLOCK sequences in clearly separate branches together with their corresponding teleost clock proteins. This phylogenetic analysis confirms the high identity of sole amino acid sequences with their teleost and mammalian homologs and highlights their function in sole circadian system. Further studies are required to corroborate that these genes are the only Per1, Per2, and Clock existing in sole, as divergent resolution after the fish-specific genome duplication resulted in retention of different duplicates in different fish species (Wang 2008a, b).

We have shown that Per1, Per2, and Clock are widely expressed in Solea senegalensis. This is consistent with all other species in which they have been examined, including mouse (King et al. 1997; Shearman et al. 1997), zebrafish (Whitmore et al. 1998), goldfish (Velarde et al. 2009), sea
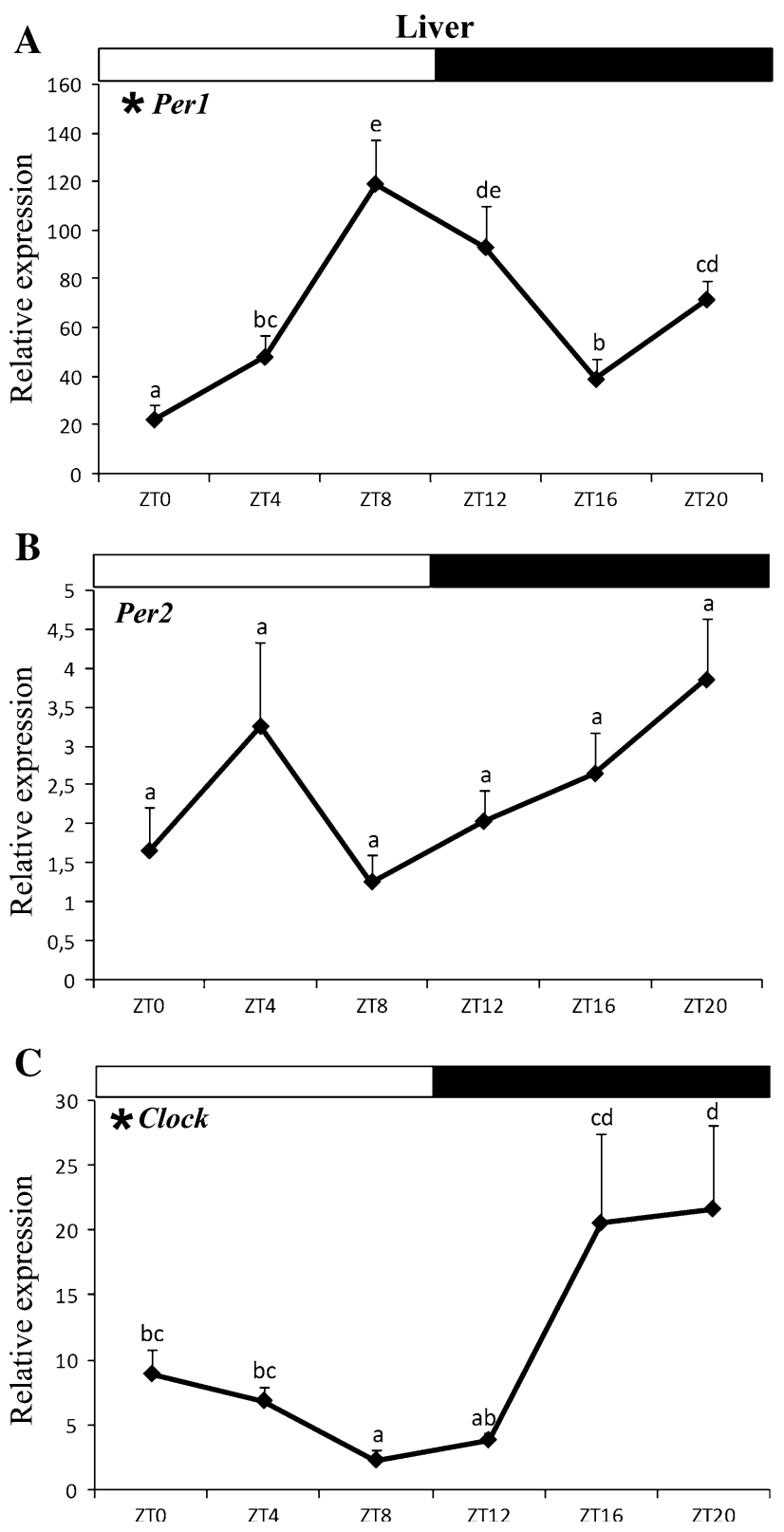

Fig. 7 Relative expression of Per1 (a), Per2 (b), and Clock (c) in the liver of Senegalese sole during the daily LD cycle. For further details, see the legend of Fig. 3

bass (Sanchez et al. 2010), and Drosophila (Hall 1995). Similar ubiquitous spatial expression pattern have been reported in many species for other clock genes as Per3, Bmal, or Cry (Cermakian et al. 2000; Kobayashi et al. 2000; Miyamoto and Sancar 1999; Zylka et al. 1998), and there are now several examples of peripheral (non-neural) tissues that contain endogenous circadian clocks (Plautz et al. 1997; Whitmore et al. 1998; Yamazaki et al. 2000). The presence of Per1, Per2, and Clock, together with Per3 (Martin-Robles et al. 2011) mRNAs in central and peripheral tissues reinforce that sole may also have multiple clocks dispersed through the body. 
In sole retina, Perl and Clock transcripts were rhythmic but Per 2 did not show significant daily variations. Per1 expression was highest at midnight (ZT 18.12) and minimum mRNA levels were observed during daytime (ZT 4ZT 8). This profile is quite similar to that described for the retina in other diurnal fish species as the golden rabbitfish (Siganus gutatus), goldfish (Carassius auratus), and rainbow trout (Oncorhynchus mykiss) (Park et al. 2007; Patiño et al. 2011; Velarde et al. 2009) and $6 \mathrm{~h}$-advanced to that found in Xenopus laevis retina, where Perl peak expression occurs during the time of light onset, at ZT 0 (Zhuang et al. 2000). However, it differs considerably from that previously reported for mammals, where Perl peak expression in retina arises later during daytime (Peirson et al. 2006; Tosini et al. 2007; Zylka et al. 1998). In the retina of sole, Clock peaked during midday at ZT 6.38, while minimum expression values were reached at night. It is interesting to note that this pattern of rhythmicity differs slightly from that reported in fish species as rainbow trout and zebrafish (Patiño et al. 2011; Whitmore et al. 1998; Zhdanova et al. 2008), where retinal Clock showed a major peak of expression at the end of the light phase (ZT9 and ZT11 for rainbow trout and zebrafish, respectively) and the onset of the night (ZT12 and ZT15 for rainbow trout and zebrafish, respectively). In addition, Clock is constitutively expressed in the retina of quail (Coturnix japonica) and Xenopus (Yoshimura et al. 2000; Zhu et al. 2000), but contradictory results have been obtained in both avian and mammalian species depending on the techniques used and the species studied (Helfer et al. 2006; Iuvone et al. 2005). The regulatory mechanisms responsible for these differences in Clock mRNA levels in the retina and their significance on the circadian clock function are unknown. Surprisingly, Per2 expression was arrhythmic in sole retina, although a daily rhythm of this gene has been described in the retina of several species (Chaurasia et al. 2006; Kamphuis et al. 2005; Velarde et al. 2009; Yoshimura et al. 2000; Zhuang et al. 2000). Transcript levels of Per2 change rapidly in response to variations in the light conditions, and a role for this clock gene in phase resetting by light in Xenopus, zebrafish, quail and mammals has been suggested (Besharse et al. 2004; Namihira et al. 2001; Pando et al. 2001; Shearman et al. 1997; Yoshimura et al. 2000; Zylka et al. 1998). The lack of rhythmicity in sole retina could be related to shifted phases of Per2 expression in different retinal cell types (Tosini et al. 2008). Alternatively, it could be associated with seasonal variations in Per2 retinal rhythms and/or to the benthonic habits of sole, which determines differences in light exposition (i.e., light intensity and/or spectrum) in relation to pelagic species. Taken together, our results pointed to interspecies differences in circadian organization of the vertebrate retina, as has been suggested before (Iuvone et al. 2010).
Daily expression analysis of clock genes in discrete brain areas showed that Perl was rhythmically expressed in the optic tectum and Per2 in the diencephalon. Temporal expression of Clock mRNA levels fits a cosinor function also in sole cerebellum, although these data did not show statistically significant variations over time by ANOVA. In contrast, in the optic tectum, Per 2 mRNA levels showed significant daily variations only by ANOVA. Rhythmic expression of Perl in sole optic tectum resembled the Perl daily profile observed in retina, although it exhibited a phase delay and the amplitude was higher in the photoreceptive organ, as occurred for Per3 (Martin-Robles et al. 2011). Tectal Perl acrophase was placed at the end of the night (ZT 22.27), in agreement with Perl rhythms recently reported in rabbitfish, sea bass, or zebrafish brain (LopezOlmeda et al. 2010; Park et al. 2007; Sanchez et al. 2010; Sanchez and Sanchez-Vazquez 2009). In the diencephalon, only Per2 transcript exhibited daily oscillations by both ANOVA and cosinor analyses, its expression being higher during daytime. To the best of our knowledge, precise data of Per2 daily expression are not available in fish diencephalon, but Perl transcripts also peaked in the rainbow trout hypothalamus during daytime at ZT3 (Patiño et al. 2011). The diencephalon and the optic tectum receive or integrate information from sensory organs in teleost fish (e.g., retinal and pineal projections) and contain high concentration of melatonin receptors in most species including sole (Confente et al. 2010; Herrera-Perez et al. 2010; Mazurais et al. 1999; Oliveira et al. 2008). In addition, as mentioned before, Per2 is light-inducible in Xenopus, zebrafish, quail, and mammals, and it has been shown that some diencephalic areas are photosensitive in different non-mammalian vertebrates (Falcon et al. 2010; Kojima et al. 2000; Menaker et al. 1997). It should be noted that no central master pacemaker has been identified in fish yet. Therefore, a more anatomically precise approach appears necessary to interpret the presence or the lack of rhythmicity of some clock genes in particular neural regions. Furthermore, whether diencephalic expression of Per2 is present in putative deep brain photoreceptors or in cells receiving direct retinal/ pineal projections remains to be investigated in sole.

Together with the retina, the liver is one of the tissues that exhibited robust rhythms in sole, showing significant daily variations for Perl and Clock. In this case, both genes displayed an $8-12 \mathrm{~h}$ phase shift compared to retina and optic tectum, with their acrophases at ZT 9.59 and ZT 18.56 , respectively. This result could suggest an uncoupling from the sole neural tissues and entrainment of the liver oscillator to cues different from light, highlighting a possible role of feeding time. Actually, entrainment of peripheral oscillators by feeding has been demonstrated in fish (Cavallari et al. 2011; Feliciano et al. 2011; Lopez-Olmeda et al. 2010) and mammals (Damiola et al. 2000; Stokkan et al. 
2001). In addition to the phase shift, the higher mesor and amplitude of Perl in sole liver, compared to the retina and the optic tectum and also to Per2 and Clock, further suggest that this gene could play an important role in feeding entrainment, being more susceptible to feeding cues. This result is consistent with that reported in goldfish where the negative elements Perl and Cry3 also showed higher amplitude rhythms in liver compared to the brain, pointing to the liver as more sensitive to feeding entrainment (Feliciano et al. 2011). However, further studies are needed to clarify how different light (LD vs. constant conditions) and feeding schedules (e.g., daytime, nighttime, or random restricted feeding) are able to entrain the brain and liver oscillators in sole.

In summary, we have developed new and valuable tools to explore the molecular basis of the Senegalese sole circadian system, providing original information on clock genes from the positive (Clock) and negative (Perl, Per2) molecular loops in this species. Such clock genes were expressed in all analyzed tissues of sole and displayed significant daily oscillations, which were particularly evident in the retina, optic tectum, and liver. Neural (brain and retina) and peripheral (liver) tissues showed marked differences in phase, suggesting the existence of different entraining cues (light vs. feeding time) and emphasizing the great flexibility of the fish circadian system. These results could be useful to deepen the understanding of how reproductive, metabolic, developmental, and behavioral rhythms are controlled in this species, and might provide valuable information to improve the practices in sole aquaculture.

Acknowledgments This work was supported by grants from the Spanish Ministerio de Ciencia e Innovación (MICINN, AGL200766507-C02-01) and Junta de Andalucía (P06-AGR-01939) to José A. Muñoz-Cueto, and a predoctoral fellow of the Spanish MICINN (BES2005-8629) to Águeda J. Martín-Robles. We thank Francesca Confente for her help in sampling. We also thank all staff from the "Planta de Cultivos Marinos" (University of Cádiz) for maintaining the animals used in these studies. Sequencing analyses were performed in Servicio Central de Ciencia y Tecnología (University of Cádiz). This is the contribution $n^{\circ} 1$ from the CEIMAR Journal Publication Series.

\section{References}

Balsalobre A (2002) Clock genes in mammalian peripheral tissues. Cell Tissue Res 309:193-199

Bayarri MJ, Muñoz-Cueto JA, Lopez-Olmeda JF, Vera LM, Rol de Lama MA, Madrid JA, Sanchez-Vazquez FJ (2004) Daily locomotor activity and melatonin rhythms in Senegal sole (Solea senegalensis). Physiol Behav 81:577-583

Besharse JC, Zhuang M, Freeman K, Fogerty J (2004) Regulation of photoreceptor Per1 and Per2 by light, dopamine and a circadian clock. Eur J Neurosci 20:167-174

Blanco-Vives B, Aliaga-Guerrero M, Cañavate JP, Muñoz-Cueto JA, Sanchez-Vazquez FJ (2011a) Does lighting manipulation during incubation affect hatching rhythms and early development of sole? Chronobiol Int 28:300-306
Blanco-Vives B, Vera LM, Ramos J, Bayarri MJ, Mañanos E, Sanchez-Vazquez FJ (2011b) Exposure of larvae to daily thermocycles affects gonad development, sex ratio, and sexual steroids in Solea senegalensis, Kaup. J Exp Zool A Ecol Genet Physiol 315:162-169

Blanco-Vives B, Aliaga-Guerrero M, Cañavate JP, García-Mateos G, Martín-Robles AJ, Herrera-Pérez P, Muñoz-Cueto JA, SánchezVázquez FJ (2012) Metamorphosis induces a light-dependent switch in Senegalese sole (Solea senegalensis, Kaup) from diurnal to nocturnal behavior. J Biol Rhythms 27:135-145

Cavallari N, Frigato E, Vallone D, Fröhlich N, Lopez-Olmeda JF, Foà A, Berti R, Sánchez-Vázquez FJ, Bertolucci C, Foulkes NS (2011) A blind circadian clock in cavefish reveals that opsins mediate peripheral clock photoreception. PLoS Biol 9:e1001142

Cermakian N, Whitmore D, Foulkes NS, Sassone-Corsi P (2000) Asynchronous oscillations of two zebrafish CLOCK partners reveal differential clock control and function. Proc Natl Acad Sci USA 97:4339-4344

Challet E, Mendoza J (2010) Metabolic and reward feeding synchronises the rhythmic brain. Cell Tissue Res 341:1-11

Chaurasia SS, Pozdeyev N, Haque R, Visser A, Ivanova TN, Iuvone PM (2006) Circadian clockwork machinery in neural retina: evidence for the presence of functional clock components in photoreceptor-enriched chick retinal cell cultures. Mol Vis 12:215-223

Confente F, Rendon MC, Besseau L, Falcon J, Muñoz-Cueto JA (2010) Melatonin receptors in a pleuronectiform species, Solea senegalensis: cloning, tissue expression, day-night and seasonal variations. Gen Comp Endocrinol 167:202-214

Damiola F, Le Minh N, Preitner N, Kornmann B, Fleury-Olela F, Schibler U (2000) Restricted feeding uncouples circadian oscillators in peripheral tissues from the central pacemaker in the suprachiasmatic nucleus. Genes Dev 14:2950-2961

Falcon J, Migaud H, Muñoz-Cueto JA, Carrillo M (2010) Current knowledge on the melatonin system in teleost fish. Gen Comp Endocrinol 165:469-482

Feliciano A, Vivas Y, de Pedro N, Delgado MJ, Velarde E, Isorna E (2011) Feeding time synchronizes clock gene rhythmic expression in brain and liver of goldfish (Carassius auratus). J Biol Rhythms 26:24-33

Galtier N, Gouy M, Gautier C (1996) SEAVIEW and PHYLO_WIN: Two graphic tools for sequence alignment and molecular phylogeny. Comput Appl Biosci 12:543-548

Guilding C, Piggins HD (2007) Challenging the omnipotence of the suprachiasmatic timekeeper: are circadian oscillators present throughout the mammalian brain? Eur J Neurosci 25:31953216

Hall JC (1995) Tripping along the trail to the molecular mechanisms of biological clocks. Trends Neurosci 18:230-240

Helfer G, Fidler AE, Vallone D, Foulkes NS, Brandstaetter R (2006) Molecular analysis of clock gene expression in the avian brain. Chronobiol Int 23:113-127

Herrera-Perez P, Rendon MC, Besseau L, Sauzet S, Falcon J, MuñozCueto JA (2010) Melatonin receptors in the brain of the European sea bass: an in situ hybridization and autoradiographic study. J Comp Neurol 518:3495-3511

Hirayama J, Sassone-Corsi P (2005) Structural and functional features of transcription factors controlling the circadian clock. Curr Opin Genet Dev 15:548-556

Isorna E, El M'rabet A, Confente F, Falcon J, Muñoz-Cueto JA (2009) Cloning and expression of arylalkylamine $N$-acetyltranferase-2 during early development and metamorphosis in the sole Solea senegalensis. Gen Comp Endocrinol 161:97-102

Isorna E, Aliaga-Guerrero M, M'Rabet AE, Servili A, Falcon J, MuñozCueto JA (2011) Identification of two arylalkylamine $N$-acetyltranferase 1 genes with different developmental expression profiles in the flatfish Solea senegalensis. J Pineal Res 51:434-444 
Iuvone PM, Tosini G, Pozdeyev N, Haque R, Klein DC, Chaurasia SS (2005) Circadian clocks, clock networks, arylalkylamine $N$-acetyltransferase, and melatonin in the retina. Prog Retin Eye Res $24: 433-456$

Iuvone PM, Velarde E, Delgado MJ, Alonso-Gomez AL, Haque R (2010) Circadian clocks in retina of goldfish. In: Kulczykowska E, Popek W, Kapoor BG (eds) Biological clock in fish. Science Publisher, Lebanon, pp 251-264

Kamphuis W, Cailotto C, Dijk F, Bergen A, Buijs RM (2005) Circadian expression of clock genes and clock-controlled genes in the rat retina. Biochem Biophys Res Commun 330:18-26

King DP, Zhao Y, Sangoram AM, Wilsbacher LD, Tanaka M, Antoch MP, Steeves TD, Vitaterna MH, Kornhauser JM, Lowrey PL, Turek FW, Takahashi JS (1997) Positional cloning of the mouse circadian clock gene. Cell 89:641-653

Kobayashi Y, Ishikawa T, Hirayama J, Daiyasu H, Kanai S, Toh H, Fukuda I, Tsujimura T, Terada N, Kamei Y, Yuba S, Iwai S, Todo $\mathrm{T}$ (2000) Molecular analysis of zebrafish photolyase/cryptochrome family: two types of cryptochromes present in zebrafish. Genes Cells 5:725-738

Kojima D, Mano H, Fukada Y (2000) Vertebrate ancient-long opsin: a green-sensitive photoreceptive molecule present in zebrafish deep brain and retinal horizontal cells. J Neurosci 20:2845-2851

Lahiri K, Foulkes NS (2010) Fishing for links between the circadian clock and cell cycle. In: Kulczykowska E, Popek W, Kapoor BG (eds) Biological clock in fish. Science Publisher, Lebanon, pp 93-110

Lee C, Etchegaray JP, Cagampang FR, Loudon AS, Reppert SM (2001) Posttranslational mechanisms regulate the mammalian circadian clock. Cell 107:855-867

Livak KJ, Schmittgen TD (2001) Analysis of relative gene expression data using real-time quantitative PCR and the 2-[Delta][Delta]CT method. Methods 25:402-408

Lopez-Olmeda JF, Tartaglione EV, de la Iglesia HO, SanchezVazquez FJ (2010) Feeding entrainment of food-anticipatory activity and per1 expression in the brain and liver of zebrafish under different lighting and feeding conditions. Chronobiol Int 27:1380-1400

Martin-Robles AJ, Isorna E, Whitmore D, Muñoz-Cueto JA, Pendon C (2011) The clock gene Period3 in the nocturnal flatfish Solea senegalensis: molecular cloning, tissue expression and daily rhythms in central areas. Comp Biochem Physiol A: Mol Integr Physiol 159:7-15

Mazurais D, Brierley I, Anglade I, Drew J, Randall C, Bromage N, Michel D, Kah O, Williams LM (1999) Central melatonin receptors in the rainbow trout: comparative distribution of ligand binding and gene expression. J Comp Neurol 409:313-324

Menaker M, Moreira LF, Tosini G (1997) Evolution of circadian organization in vertebrates. Braz J Med Biol Res 30:305-313

Meyer A, Van de Peer Y (2005) From 2R to 3R: evidence for a fishspecific genome duplication (FSGD). BioEssays 27:937-945

Migaud H, Davie A, Martinez Chavez CC, Al-Khamees S (2007) Evidence for differential photic regulation of pineal melatonin synthesis in teleosts. J Pineal Res 43:327-335

Miyamoto Y, Sancar A (1999) Circadian regulation of cryptochrome genes in the mouse. Brain Res Mol Brain Res 71:238-243

Namihira M, Honma S, Abe H, Masubuchi S, Ikeda M, Honma K-i (2001) Circadian pattern, light responsiveness and localization of rPer1 and rPer2 gene expression in the rat retina. NeuroReport 12:471-475

Navarro DB, Rubio VC, Luz RK, Madrid JA, Sanchez-Vazquez FJ (2009) Daily feeding rhythms of Senegalese sole under laboratory and farming conditions using self-feeding systems. Aquaculture 291:130-135

Nelson W, Tong YL, Lee JK, Halberg F (1979) Methods for cosinorrhythmometry. Chronobiologia 6:305-323
Oliveira C, Lopez-Olmeda JF, Delgado MJ, Alonso-Gomez AL, Sanchez-Vazquez FJ (2008) Melatonin binding sites in Senegal sole: day/night changes in density and location in different regions of the brain. Chronobiol Int 25:645-652

Oliveira C, Dinis MT, Soares F, Cabrita E, Pousao-Ferreira P, Sanchez-Vazquez FJ (2009) Lunar and daily spawning rhythms of Senegal sole Solea senegalensis. J Fish Biol 75:61-74

Oliveira C, Duncan NJ, Pousao-Ferreira P, Mananos E, SanchezVazquez FJ (2010) Influence of the lunar cycle on plasma melatonin, vitellogenin and sex steroids rhythms in Senegal sole, Solea senegalensis. Aquaculture 306:343-347

Pando MP, Sassone-Corsi P (2002) Unraveling the mechanisms of the vertebrate circadian clock: zebrafish may light the way. BioEssays 24:419-426

Pando MP, Pinchak AB, Cermakian N, Sassone-Corsi P (2001) A cellbased system that recapitulates the dynamic light-dependent regulation of the vertebrate clock. Proc Natl Acad Sci USA 98:10178-10183

Park JG, Park YJ, Sugama N, Kim SJ, Takemura A (2007) Molecular cloning and daily variations of the Period gene in a reef fish Siganus guttatus. J Comp Physiol A Neuroethol Sens Neural Behav Physiol 193:403-411

Patiño MA, Rodriguez-Illamola A, Conde-Sieira M, Soengas JL, Miguez JM (2011) Daily rhythmic expression patterns of Clock1a, Bmal1, and Per1 genes in retina and hypothalamus of the rainbow trout, Oncorhynchus mykiss. Chronobiol Int 28:381-389

Peirson SN, Butler JN, Duffield GE, Takher S, Sharma P, Foster RG (2006) Comparison of clock gene expression in SCN, retina, heart, and liver of mice. Biochem Biophys Res Commun 351:800-807

Plautz JD, Kaneko M, Hall JC, Kay SA (1997) Independent photoreceptive circadian clocks throughout Drosophila. Science 278:1632-1635

Reppert SM, Weaver DR (2002) Coordination of circadian timing in mammals. Nature 418:935-941

Sanchez JA, Sanchez-Vazquez FJ (2009) Feeding entrainment of daily rhythms of locomotor activity and clock gene expression in zebrafish brain. Chronobiol Int 26:1120-1135

Sanchez JA, Madrid JA, Sanchez-Vazquez FJ (2010) Molecular cloning, tissue distribution, and daily rhythms of expression of per1 gene in European sea bass (Dicentrarchus labrax). Chronobiol Int 27:19-33

Shearman LP, Zylka MJ, Weaver DR, Kolakowski LF Jr, Reppert SM (1997) Two period homologs: circadian expression and photic regulation in the suprachiasmatic nuclei. Neuron 19:1261-1269

Stokkan KA, Yamazaki S, Tei H, Sakaki Y, Menaker M (2001) Entrainment of the circadian clock in the liver by feeding. Science 291:490-493

Tamai TK, Carr AJ, Whitmore D (2005) Zebrafish circadian clocks: cells that see light. Biochem Soc Trans 33:962-966

Tosini G, Kasamatsu M, Sakamoto K (2007) Clock gene expression in the rat retina: effects of lighting conditions and photoreceptor degeneration. Brain Res 1159:134-140

Tosini G, Pozdeyev N, Sakamoto K, Iuvone PM (2008) The circadian clock system in the mammalian retina. BioEssays 30:624-633

Velarde E, Haque R, Iuvone PM, Azpeleta C, Alonso-Gomez AL, Delgado MJ (2009) Circadian clock genes of goldfish, Carassius auratus: cDNA cloning and rhythmic expression of period and cryptochrome transcripts in retina, liver, and gut. J Biol Rhythms 24:104-113

Vera LM, De Oliveira C, Lopez-Olmeda JF, Ramos J, Mananos E, Madrid JA, Sanchez-Vazquez FJ (2007) Seasonal and daily plasma melatonin rhythms and reproduction in Senegal sole kept under natural photoperiod and natural or controlled water temperature. J Pineal Res 43:50-55 
Wang H (2008a) Comparative analysis of period genes in teleost fish genomes. J Mol Evol 67:29-40

Wang H (2008b) Comparative analysis of teleost fish genomes reveals preservation of different ancient clock duplicates in different fishes. Mar Genom 1:69-78

Whitmore D, Foulkes NS, Strahle U, Sassone-Corsi P (1998) Zebrafish Clock rhythmic expression reveals independent peripheral circadian oscillators. Nat Neurosci 1:701-707

Whitmore D, Foulkes NS, Sassone-Corsi P (2000) Light acts directly on organs and cells in culture to set the vertebrate circadian clock. Nature 404:87-91

Yamazaki S, Numano R, Abe M, Hida A, Takahashi R, Ueda M, Block GD, Sakaki Y, Menaker M, Tei H (2000) Resetting central and peripheral circadian oscillators in transgenic rats. Science 288:682-685

Yoshimura T, Suzuki Y, Makino E, Suzuki T, Kuroiwa A, Matsuda Y, Namikawa T, Ebihara S (2000) Molecular analysis of avian circadian clock genes. Brain Res Mol Brain Res 78:207-215
Zhdanova IV, Yu L, Lopez-Patiño M, Shang E, Kishi S, Guelin E (2008) Aging of the circadian system in zebrafish and the effects of melatonin on sleep and cognitive performance. Brain Res Bull 75:433-441

Zhu H, LaRue S, Whiteley A, Steeves TD, Takahashi JS, Green CB (2000) The Xenopus clock gene is constitutively expressed in retinal photoreceptors. Brain Res Mol Brain Res 75:303-308

Zhuang M, Wang Y, Steenhard BM, Besharse JC (2000) Differential regulation of two period genes in the Xenopus eye. Brain Res Mol Brain Res 82:52-64

Zylka MJ, Shearman LP, Weaver DR, Reppert SM (1998) Three period homologs in mammals: differential light responses in the suprachiasmatic circadian clock and oscillating transcripts outside of brain. Neuron 20:1103-1110 